\title{
Reduced CoronaVac vaccine antibody response in patients with chronic kidney disease
}

\author{
Tekin Akpolat ${ }^{1}$ (])
}

Received: 1 May 2021 / Accepted: 6 October 2021 / Published online: 18 October 2021

(c) The Author(s), under exclusive licence to Springer Nature B.V. 2021

\section{Editor,}

Chronic kidney disease (CKD) is a risk factor for higher morbidity and mortality for coronavirus (COVID-19) infection caused by severe acute respiratory syndrome coronavirus 2. There are different vaccines against COVID-19 infection. CoronaVac is an inactivated virus vaccine and data regarding its efficacy is limited [1,2]. The data about adults older than 60 years and CKD is even more limited. There are a few studies about COVID-19 vaccines in CKD patients, but they are with mRNA vaccines [3-5]. The purpose of this study is to evaluate antibody responses to CoronaVac vaccine in patients with CKD and compare it to patients without CKD among subjects older than 60 years of age.

Thirty-eight subjects (mean age 71, range 61-88) were included in this study, only 10 of them had CKD. Causes of CKD were diabetes mellitus and hypertension. Non-CKD group was younger (68 vs 77 years) and did not have any active chronic disease such as malignancy, uncontrolled hypertension. Patients having previous COVID-19 infection were excluded.

All subjects got two doses ( $3 \mathrm{mcg}, 28$ days apart) of CoronaVac vaccine [2]. Antibody results were collected by three ways: talking face to face, telephone calls, and Whatsapp messages. Results of antibody responses were categorised into two groups: positive or negative. Positive test means high antibody titers any time after second dose and negative test means no antibody response 28 days after second dose.

Spike antibodies were positive in 33 of $38(87 \%)$ of the subjects, all of the 28 subjects without CKD had a positive test, and common characteristics of five negative patients were the presence of both CKD (eGFR $<10,24,39,43$ and $64 \mathrm{ml} / \mathrm{min}$ ) and diabetes mellitus/insulin resistance. Only

Tekin Akpolat

tekinakpolat@yahoo.com

1 Department of Internal Medicine and Nephrology, Istinye University School of Medicine, Istanbul, Turkey five of ten patients (50\%) with CKD had a positive antibody. The number of CKD patients having positive antibody was significantly lower $\left(x^{2}=12.0, p<0.01\right)$ compared to subjects without CKD.

It seems that CoronaVac has a safe side effect profile; however, there are concerns about its efficacy.

This study documents less antibody response to CoronaVac vaccine in patients with CKD, but there are some limitations:

1. The number of patients was limited

2. Only subjects older than 60 years of age were included

3. Antibody titers were studied in different laboratories.

Although we expect that positive antibody levels protect from COVID-19 infection and we also expect $T$ cell related protection after inactivated vaccine, we do not have enough published data about efficacy of CoronaVac vaccine. The information about its efficacy in subjects older than 60 years and/or CKD is even more scarce. To our knowledge, this observation is the first evaluating antibody response to COVID-19 vaccination in patients CKD. With very preliminary and limited data, it seems that CoronaVac vaccine can produce antibody responses in subjects older than 60 years, but this reponse is lower in CKD patients. Studies consisting of higher number of patients and anti-spike antibody test titers are needed for definite conclusion.

Vaccination programs must be tailored (higher and/or frequent doses) for vulnerable groups including CKD like hepatitis $B$ vaccine.

\section{Declarations}

Conflict of interest There is no conflict of interest. 


\section{References}

1. Zhang Y, Zeng G, Pan H, Li C, Hu Y, Chu K et al (2021) Safety, tolerability, and immunogenicity of an inactivated SARS-CoV-2 vaccine in healthy adults aged $18-59$ years: a randomised, doubleblind, placebo-controlled, phase 1/2 clinical trial. Lancet Infect Dis 21:181-192. https://doi.org/10.1016/S1473-3099(20)30843-4

2. Akpolat T, Uzun O (2021) Reduced mortality rate after CoronaVac vaccine among healthcare workers. J Infect. https://doi.org/ 10.1016/j.jinf.2021.06.005

3. Benotmane I, Gautier-Vargas G, Cognard N, Olagne J, Heibel F, Braun-Parvez L et al (2021) Weak anti-SARS-CoV-2 antibody response after the first injection of an mRNA COVID-19 vaccine in kidney transplant recipients. Kidney Int. https://doi.org/ 10.1016/j.kint.2021.03.014
4. Agur T, Ben-Dor N, Goldman S, Lichtenberg S, Michal HermanEdelstein $M$ et al (2021) Antibody response to mRNA SARSCoV-2 vaccine among dialysis patients-a prospective cohort study. Nephrol Dial Transplant. https://doi.org/10.1093/ndt/gfab1 55

5. Grupper A, Sharon N, Finn T, Cohen R, Israel M, Agbaria A et al (2021) Humoral response to the Pfizer BNT162b2 vaccine in patients undergoing maintenance hemodialysis. CJASN. https:// doi.org/10.2215/CJN.03500321

Publisher's Note Springer Nature remains neutral with regard to jurisdictional claims in published maps and institutional affiliations. 